\title{
Synergistic Cytotoxicity of Melatonin and New-generation Anticancer Drugs Against Leukemia Lymphocytes But Not Normal Lymphocytes
}

\author{
ZHIVKO ZHELEV ${ }^{1,2}$, DONIKA IVANOVA ${ }^{1}$, RUMIANA BAKALOVA $^{3,4}$, ICHIO AOKI $^{3}$ and TATSUYA HIGASHI ${ }^{3}$ \\ ${ }^{1}$ Medical Faculty, Trakia University, Stara Zagora, Bulgaria; \\ ${ }^{2}$ Institute of Biophysics \& Biomedical Engineering, Bulgarian Academy of Sciences, Sofia, Bulgaria; \\ ${ }^{3}$ Department of Molecular Imaging and Theranostics, National Institute of Radiological Sciences, \\ National Institute for Quantum and Radiological Science and Technology, Chiba, Japan; \\ ${ }^{4}$ Medical Faculty, Sofia University St. Kliment Ohridski, Sofia, Bulgaria
}

\begin{abstract}
The present study demonstrates specific sensitization of leukemia lymphocytes towards anticancer drugs using melatonin and clarifies the role of reactive oxygen species (ROS) for induction of apoptosis. The study covers four conventional and 11 new-generation anticancer drugs. Four parameters were analyzed simultaneously in leukemia and normal lymphocytes treated with drug, melatonin, or their combination: cell viability, induction of apoptosis, level of reactive oxygen species (ROS), and level of protein-carbonyl products. Almost all investigated combinations of melatonin with new-generation anticancer drugs were characterized by synergistic cytotoxicity towards leukemia lymphocytes, while the combinations with conventional drugs exhibited additive or antagonistic effects on cell viability. In leukemia lymphocytes, the additive cytotoxicity of doxorubicin plus melatonin was accompanied by low levels of ROS and protein-carbonyl products, as well as by suppression of apoptosis. In normal lymphocytes, none of the studied parameters changed significantly compared to cells treated with doxorubicin only. The combinations of everolimus plus melatonin and barasertib plus melatonin exhibited impressive synergistic cytotoxic effects on leukemia lymphocytes but did not affect the viability of normal lymphocytes. In leukemia cells, the synergistic cytotoxicity was accompanied by strong induction of apoptosis but a decrease of ROS to a level below that of the control. In normal lymphocytes, these combinations did not affect the level
\end{abstract}

Correspondence to: Rumiana Bakalova, Ph.D., D.Sci., Department of Molecular Imaging and Theranostics, National Institute of Radiological Sciences (NIRS), National Institute for Quantum and Radiological Science and Technology (QST), 4-9-1 Anagawa, Inageku, Chiba 263-8555, Japan. E-mail: bakalova.rumiana@qst.go.jp

Key Words: Melatonin, anticancer drugs, leukemia lymphocytes, normal lymphocytes, reactive oxygen species, apoptosis. of ROS nor of protein-carbonyl products, and did not induce apoptosis. The data suggest that melatonin is a promising supplementary component in chemotherapy which allows the therapeutic doses of anticancer drugs to be reduced, minimizing their side-effects.

It is widely accepted that the efficiency of conventional anticancer drugs is due to induction of oxidative stress in cancer cells. However, their harmful side-effects are also attributed to the increased production of reactive oxygen species (ROS) and disruption of the redox-homeostasis of normal cells and tissues (1-4). In the past two decades, a large number of studies have shown that natural or synthetic compounds which modulate the cellular redox status exhibit anticancer effects. The data are summarized in several excellent review articles published recently (5-8). Some of the described redox modulators induce production of ROS, but in most cases, their anticancer activity is related to the influence on signaling pathways for regulation of physiological processes, rather than by induction of strong oxidative stress and damage to biomacromolecules (5-10).

The pituitary hormone melatonin ( $N$-acetyl-5-methoxytryptamine) is of great interest as an endogenous redox modulator with anticancer activity. Melatonin is responsible for the synchronization of the circadian rhythm of physiological functions in mammals (11-13). It has been shown that melatonin plays a direct role in mitochondrial homeostasis $(11,14-16)$, which may explain its protective effect on variety of diseases accompanied by mitochondrial dysfunction as a primary or secondary cause of the pathology, such as: Parkinson's disease, Alzheimer's disease, epilepsy, aging, ischemia-reperfusion and sepsis (11, 14, 17-20). Melatonin also acts as an antioxidant - directly as a scavenger of $\operatorname{ROS}(14,15,17,18,21)$, and indirectly through regulating the expression and activities of antioxidant enzymes and nitric oxide synthase (NOS) $(11,22-24)$. 
In pharmaceutically-relevant doses, melatonin inhibits tumor growth and has a potential therapeutic value in treating breast cancer, prostate cancer, melanoma and gastrointestinal cancer $(11,14,25-27)$. For example, a strong pro-apoptotic effect of melatonin (at $100 \mathrm{nM}$ ) was observed in MCF-7 breast tumor cells after 20 hours of treatment (28). The effect was accompanied by disruption of mitochondrial respiration and $\sim 40-60 \%$ loss of MCF-7 cells. Melatonin also inhibited growth and induced apoptosis of MOLT-3 human leukemia cells (29). In this case, the intrinsic apoptotic pathway has a key role in melatonin-induced cell death because of activation of the caspase cascade, an increase of the BAX/BCL2 ratio and of the cytochrome $c$ level in the cytosol (29). Up-regulation of $B A X$ in response to melatonin has been reported in HL-60 human myeloid cells, pancreatic carcinoma, and HepG2 liver carcinoma cells (30-32). Both the intrinsic (mitochondrial-mediated) and the extrinsic (receptor-mediated) pathways of apoptosis are activated by melatonin in cancer but not in normal cells $(27,30,33,34)$. It seems that melatonin has differential effects on the normal cells especially related to the regulation of apoptosis. The reason for pro-apoptotic selectivity and efficiency of melatonin in cancer is still unclear. Most likely, melatonin affects biochemical pathways that are unique to cancer. These findings suggest the potential of melatonin in the preferential killing of cancer cells and preservation of normal cells and tissues - a dream therapeutic strategy for decades.

The aim of the present study was to clarify the role of melatonin as a redox modulator and chemosensitizer in cancer and normal cells. We investigated: (i) the possibility of sensitizing leukemia lymphocytes to anticancer drugs using melatonin in pharmacologically permissible doses; (ii) combinations of drugs and melatonin with synergistic cytotoxic effect on leukemia lymphocytes and determined their cytotoxicity towards normal lymphocytes; (iii) and the role of ROS in the induction of apoptosis and cytotoxicity by those combinations. The study covers 15 anticancer drugs - four conventional and 11 new-generation.

\section{Materials and Methods}

Cells and treatment protocol. The experiments were performed on Jurkat leukemia lymphocytes, derived from patients with acute lymphoblastic leukemia, as well as on normal lymphocytes, isolated from healthy blood donors using Lymphosepar-I (ImmunoBiological Laboratories Co., Fujioka, Japan). The cells were cultured in RPMI-1640 medium, supplemented with $10 \%$ heatinactivated fetal bovine serum and antibiotics $(100 \mathrm{U} / \mathrm{ml}$ penicillin and $100 \mu \mathrm{g} / \mathrm{ml}$ streptomycin), in a humidified atmosphere at $37^{\circ} \mathrm{C}$ with $5 \% \mathrm{CO}_{2}$. All cells were collected by centrifugation $(1,000 \times g$, $10 \mathrm{~min})$ and replaced in a fresh medium without antibiotics before treatment with anticancer drugs.

The drugs were dissolved in dimethyl sulfoxide (DMSO; suitable for cell cultures) or phosphate-buffered saline (PBS; $10 \mathrm{mM}, \mathrm{pH}$ 7.4).
The final concentration of DMSO in the cell suspension did not exceed $1 \%$. At this concentration, DMSO did not influence cell viability.

The cells $\left(1 \times 10^{6}\right.$ cells $\left./ \mathrm{ml}\right)$ were incubated with melatonin, drug, or drug plus melatonin at the following concentrations: $250 \mu \mathrm{M}$ melatonin (Sigma-Aldrich, Steinheim, Germany), $0.25 \mu \mathrm{M}$ palbociclib (Selleckchem, Houston, TX, USA), $0.5 \mu \mathrm{M}$ PI-103, $5 \mu \mathrm{M}$ (Selleckchem), everolimus (Selleckchem), $0.5 \mu \mathrm{M}$ lonafarnib (Selleckchem), $0.1 \mu \mathrm{M}$ ABT-737 (Selleckchem), $0.1 \mu \mathrm{M}$ doxorubicin (Sigma-Aldrich), $0.5 \mu \mathrm{M}$ bleomycin (Nippon Kayaku Co., Tokyo, Japan), $0.1 \mu \mathrm{M}$ AZD-7762 (Sigma-Aldrich), $0.01 \mu \mathrm{M}$ MLN-2238 (Selleckchem), $0.025 \mu \mathrm{M}$ MG-132 (Wako, Tokyo, Japan), $10 \mu \mathrm{M}$ lomustine (Sigma-Aldrich), $2.5 \mu \mathrm{M}$ cisplatin (Selleckchem), 0.025 $\mu \mathrm{M}$ BEZ-235 (Selleckchem), $0.01 \mu \mathrm{M}$ bortezomib (Selleckchem), $0.05 \mu \mathrm{M}$ or $0.01 \mu \mathrm{M}$ barasertib (Selleckchem). Drugs were applied to the cells at these concentrations (single dose) and incubated for different time intervals in a cell incubator. At each time interval, aliquots were used for cell viability assay. The selected concentrations of drugs and melatonin (applied separately) induced about $20 \%$ inhibition of cell growth

Cell viability assay. Cell viability was analyzed using trypan blue staining and Countess ${ }^{\mathrm{TM}}$ Automated Cell Counter (Invitrogen, OR, USA) at very precise standardization of the measurements. Three independent experiments (with two repetitive measurements) for each experiment were performed for each sample. Non-treated cells were used as controls. The data are presented as the mean \pm SD.

Intracellular ROS assay. The amount of ROS was analyzed using OxiSelect $^{\mathrm{TM}}$ In vitro ROS/RNS Assay Kit - Green Flourescence (Cell Biolabs., Inc., San Diego, CA, USA). The method is based on the use of fluorogenic probe 2',7'-dichlorodihydrofluorescin DiOxyQ (DCFH-DiOxyQ). In the cytosol, the probe is deacetylated to the non-fluorescent 2',7'-dichlorodihydrofluorescin (DCFH). DCFH reacts with ROS and reactive nitrogen species (RNS) (predominantly $\mathrm{H}_{2} \mathrm{O}_{2}$, $\mathrm{ROO}^{*}, \mathrm{NO}, \mathrm{ONOO}^{-}$) with formation of fluorescent product 2',7'-dichlorodihydrofluorescein (DCF). The intensity of DCF fluorescence $\left(\lambda_{\mathrm{ex}}=480 \mathrm{~nm}, \lambda_{\mathrm{em}}=530 \mathrm{~nm}\right)$ is proportional of the amount of ROS/RNS in the biological sample.

The amount of ROS/RNS was calculated by calibration curve based on DCF standard solution in PBS. The measurements were performed on a Tecan Infinite F200 PRO (Tecan Austria GmbH, Mannedorf, Austria) microplate reader.

Briefly, the cells $\left(1 \times 10^{6}\right.$ cells $\left./ \mathrm{ml}\right)$ were collected by centrifugation $(1,000 \times g$ for $10 \mathrm{~min})$ and lysed by using $300 \mu \mathrm{l}$ of $0.1 \%$ sodium dodecylsulfate (SDS; dissolved in PBS) within $30 \mathrm{~min}$ on ice. The lysates were adjusted to equal protein concentration (in the range $1-10 \mathrm{mg} / \mathrm{ml}$ ) using PBS. Protein concentration was analyzed by Bradford assay. Each sample was subjected to ROS/RNS assay, according to the manufacturer's instruction.

Protein-carbonyl assay. The amount of protein-carbonyl products were analyzed using OxiSelect ${ }^{\mathrm{TM}}$ Protein Carbonyl Spectrophotometric Assay Kit (Cell Biolabs, Inc.). The most common products of protein oxidation in biological samples are the protein-carbonyl derivatives of proline, arginine, lysine and threonine, which are chemically stable and serve as markers of oxidative stress. The analysis of these products is based on derivatization of the carbonyl groups with dinitrophenylhidrazine with formation of protein-hydrazone. The amount of proteinhydrazone was detected spectrophotometrically at $375 \mathrm{~nm}$. 
Briefly, the cells $\left(1 \times 10^{6}\right.$ cells $\left./ \mathrm{ml}\right)$ were collected by centrifugation $(1,000 \times g, 10 \mathrm{~min})$ and lysed using $300 \mu \mathrm{l}$ of $0.1 \%$ SDS (dissolved in PBS) within $30 \mathrm{~min}$ on ice. The lysates were adjusted to equal protein concentration (in the range $1-10 \mathrm{mg} / \mathrm{ml}$ ) using PBS. Protein concentration was analyzed by Bradford assay. Each sample was subjected to protein-carbonyl assay, according to the manufacturer's instruction. Oxidized bovine serum albumin was used as a standard.

Apoptosis assay. The induction of apoptosis was analyzed by the expression of phosphatidylserine (PSer) on the cell surface, using FITC-Annexin V Apoptosis Detection Kit (BioVision, Milpitas, CA, USA).

Briefly, the cells $\left(1 \times 10^{6}\right.$ cells $\left./ \mathrm{ml}\right)$ were incubated with drug, melatonin or their combination, under the conditions mentioned above. At different time-points, the cells were collected by centrifugation $(1,000 \times g, 10 \mathrm{~min})$, washed twice with PBS containing $2.5 \mathrm{mM} \mathrm{CaCl}_{2}$ (annexin V-binding buffer) and resuspended in the same buffer. One hundred microliters of the suspension were incubated with $5 \mu \mathrm{l}$ of fluorescein isothiocyanate (FITC)-annexin V for $10 \mathrm{~min}$ at room temperature in the dark. The cells were washed three times with annexin V-binding buffer and were finally re-suspended in $500 \mu$ of the same buffer. FITCannexin V bound to PSer exposed on the cell surface was detected spectrofluorimetrically at $\lambda_{\mathrm{ex}}=488 \mathrm{~nm}$ and $\lambda_{\mathrm{em}}=535 \mathrm{~nm}$, using a Tecan Infinite F200 PRO (Tecan Austria GmbH) microplate reader.

Statistical analysis. The results are expressed as the mean \pm SD. Statistical analysis was performed with Student's $t$-test. A value of $p<0.05$ was considered significant.

\section{Results and Discussion}

Effect of melatonin on viability of leukemia and normal lymphocytes. The purpose of the first stage of our study was to select an optimal concentration of melatonin for application in combination with anticancer drugs. The concentration of melatonin, which led to about $20-30 \%$ cytotoxicity against leukemia lymphocytes after 48-h incubation was assumed to be 'optimal', since this cytotoxic effect allows an assessment of synergism, additivity and antagonism after combining melatonin with anticancer drug.

The data in Figure 1 demonstrate the viability of leukemia and normal lymphocytes after treatment with melatonin at different concentrations for different time intervals (24-72 hours). Melatonin in concentrations up to $500 \mu \mathrm{M}$ had no effect on the viability of normal lymphocytes (Figure 1B). However, in concentrations over $100 \mu \mathrm{M}$, it possessed low but significant cytotoxicity towards leukemia lymphocytes (Figure 1A). These observations confirm the results published in the literature about the cytotoxicity of melatonin towards leukemia cells and its protective effect on human lymphocytes $(29,30,35-38)$.

Based on the data in Figure 1, we chose to continue our experiments with melatonin at a concentration of $250 \mu \mathrm{M}$. At this concentration, melatonin causes about $20 \%$ inhibition of cell proliferation $\left(\mathrm{IC}_{20}\right)$ of Jurkat cells (Figure 1A) and

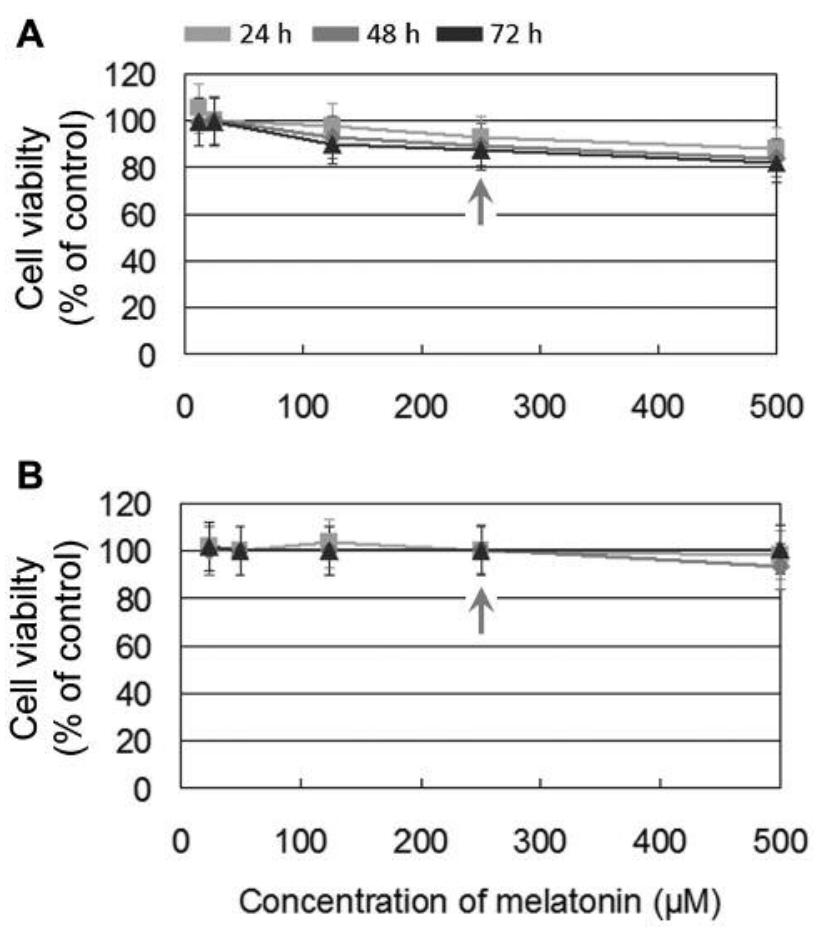

Figure 1. Effect of melatonin on viability of Jurkat leukemia lymphocytes (A) and normal lymphocytes (B) after different incubation times, showing a concentration-dependent effect. The data are the mean \pm SD from six independent experiments. The red arrow indicates the concentration of melatonin $(250 \mu \mathrm{M})$ selected for further experiments in combination with anticancer drugs.

did not exhibit cytotoxic effect on normal lymphocytes after 48-hour incubation (Figure 1B).

Effect of melatonin on cytotoxicity of anticancer drugs towards leukemia lymphocytes. In the next stage of the study, Jurkat cells were treated with melatonin and anticancer drugs, separately and in combination, for different time intervals (24, 48 , and $72 \mathrm{~h}$ ). The purpose of this experiment was to find combinations with synergistic cytotoxic effect on leukemia cells. The data are shown in Figure 2. To distinguish the synergistic effect from antagonistic/additive effects, we calculated the effect of each combination on cell proliferation as a percentage of the effect of the respective drug applied alone and compared it with the effect of that when melatonin was applied alone, as described previously (9). The red line in Figure 2B indicates the effect of melatonin alone on cell proliferation. In the case of drug plus melatonin, the data located to the left of the red line reflect synergistic cytotoxic effects, while the data located to the right of the red line represent antagonistic effects. All data matching the red line reflect an additive affect. The cytotoxicity of each drug (applied separately at the selected concentration) ranged from 

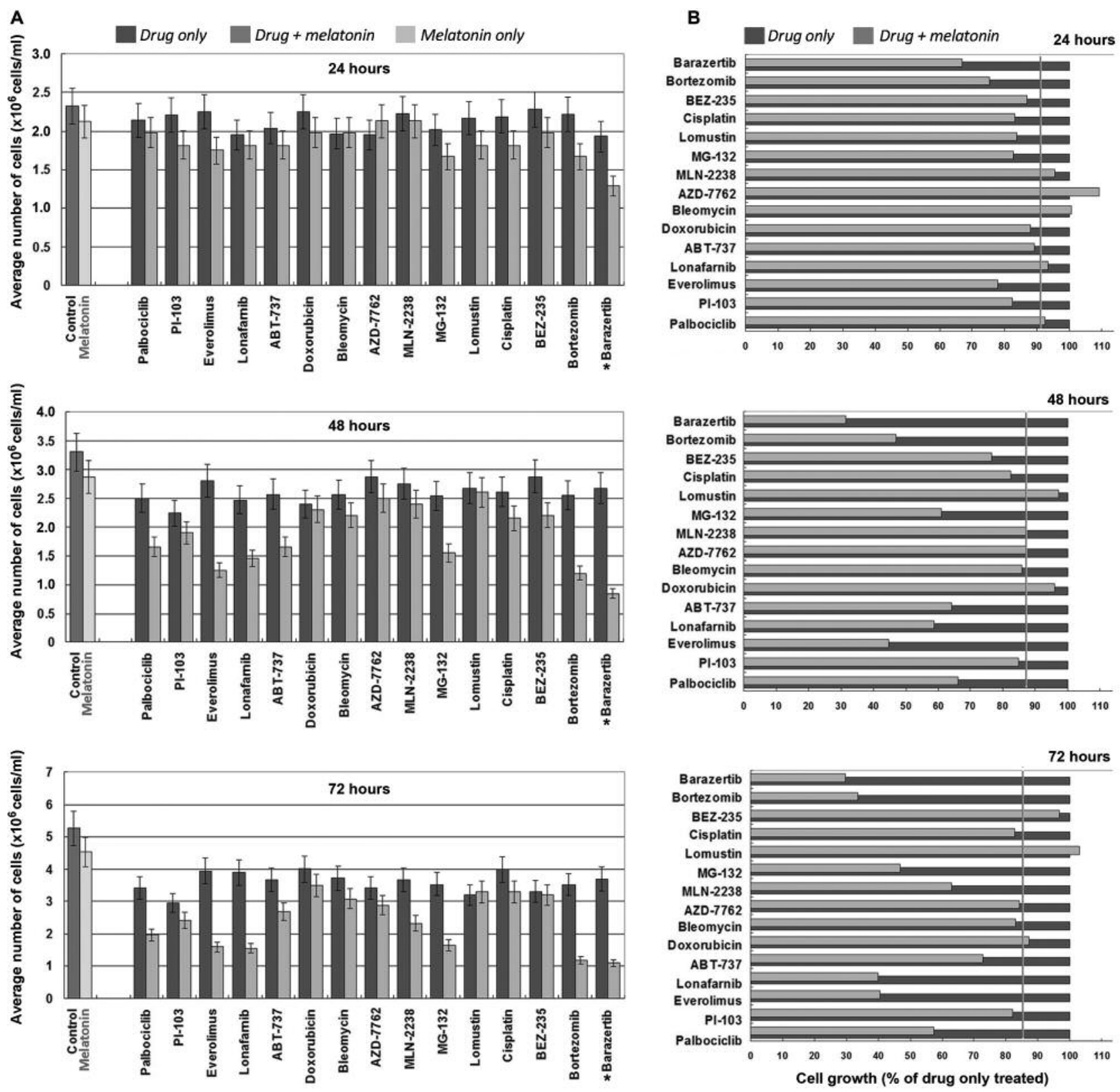

Figure 2. A: Effect of melatonin and anticancer drugs on cell proliferation of Jurkat cells after incubation for 24, 48 and 72 h. Incubation conditions: $1 \times 10^{6} \mathrm{cells} / \mathrm{ml}$, melatonin $\left(250 \mu \mathrm{M}\right.$ ) with/without drug (at concentration described in the Materials and Methods), at $37^{\circ} \mathrm{C}$ in humidified atmosphere. The data are the mean $\pm S D$ from six independent experiments. B: Effect of combination of drug plus melatonin on cell proliferation as a percentage of the effect of drug applied alone. The red line indicates the effect of melatonin on cell proliferation of cancer cells as a percentage of the control (untreated cells). *In this experiment, the concentration of barasertib was $50 \mathrm{nM}$.

about $10-20 \%$ after $24-\mathrm{h}$ incubation to about $20-30 \%$ after 48 $\mathrm{h}$ and $72-\mathrm{h}$ incubation.

Half of the combinations (drug plus melatonin) were characterized by synergistic cytotoxic effects on Jurkat cells compared to cells treated with drug only (Figure 2B). The synergism increased with incubation time. The best synergistic cytotoxic effects were observed on Jurkat cells treated with melatonin in combination with: bortezomib, barasertib, MG132, MLN-2238, everolimus, lonafarnib, and palbociclib.

Two of these synergistic combinations were selected for the next stage of the study: everolimus plus melatonin, and barasertib plus melatonin. In our recent study, we observed 

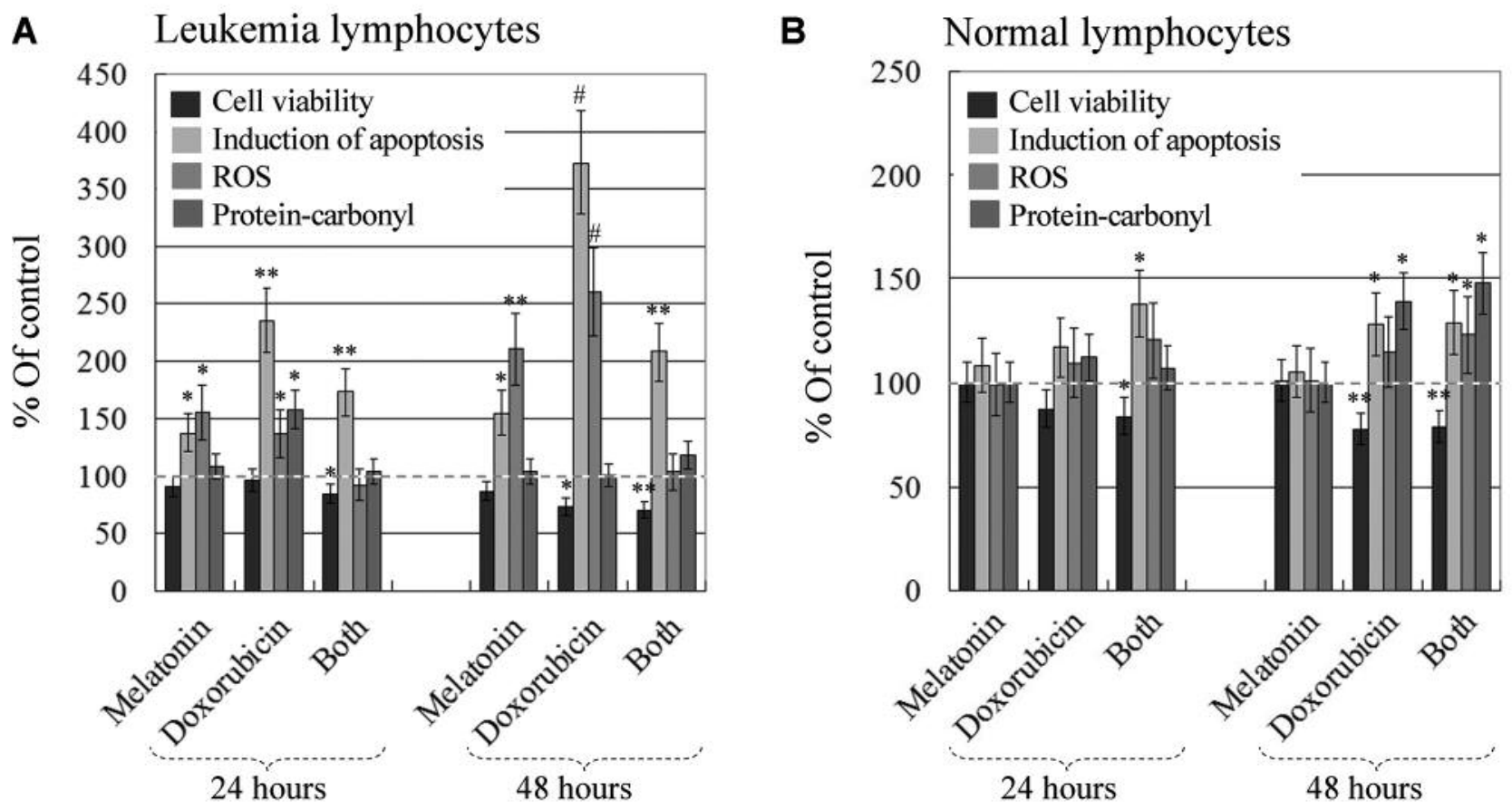

Figure 3. Effects of melatonin $(250 \mu M)$, doxorubicin $(0.1 \mu M)$ and their combination on cell viability, induction of apoptosis, level of reactive oxygen species (ROS) and level of protein-carbonyl products in Jurkat leukemia cells (A) and normal lymphocytes (B), after 24-and 48-h incubation at $37^{\circ} \mathrm{C}$ in humidified atmosphere. The data are the mean $\pm S D$ from three independent experiments. ${ }^{*} p<0.05$, $* * p<0.01,{ }^{*} p<0.001$ versus corresponding control.

that everolimus and barasertib applied alone did not induce production of ROS in leukemia and normal lymphocytes (10). In addition, we selected a combination of melatonin with a conventional anticancer drug, doxorubicin, which is known to increase ROS in cancer and normal cells $(1,10,39)$.

Effect of melatonin on doxorubicin-induced cytotoxicity, apoptosis, production of ROS and protein-carbonyl products in leukemia and normal lymphocytes. The purpose of this stage of the study was to investigate the effect of this combination on viability of normal lymphocytes and to clarify whether it was accompanied by induction of apoptosis through ROS-dependent or ROS-independent mechanism(s) in both cell types (leukemia and normal).

Doxorubicin at $0.1 \mu \mathrm{M}$ was equally cytotoxic towards leukemia and normal lymphocytes (Figure 3). Cytotoxicity increased with the time of incubation, from $~ 5-10 \%$ after $24-\mathrm{h}$ to $\sim 25 \%$ after 48 -h. This was accompanied by an increase in ROS and protein-carbonyl products in both cell types, as well as by induction of apoptosis, especially after 48-h incubation. The effects of doxorubicin were more apparent in leukemia lymphocytes than in normal lymphocytes.

Melatonin, at $250 \mu \mathrm{M}$, was slightly cytotoxic towards Jurkat cells $(\sim 10 \%$ after 48 -h incubation $)$, but not towards normal lymphocytes. In leukemia cells, cytotoxicity was accompanied by increased production of ROS and induction of apoptosis, but without effect on the level of proteincarbonyl products. This observation is a little unexpected in the context of the commonly accepted belief that melatonin is an antioxidant. Recently, some studies reported that melatonin increased production of ROS and induced apoptosis of leukemia cells (HL-60, CMK, Jurkat, MOLT-4) (40, 41). Radogna et al. also described a pro-oxidant effect of melatonin in leukocytes which was mediated by lipoxygenase via stimulation of arachidonic acid metabolism (42). A number of studies on other cancer cell lines also reported pro-oxidant effects of melatonin at physiologically relevant doses (43-47). Obviously, in some cases, melatonin acts as an antioxidant but in other cases as a pro-oxidant. Sanchez-Sanchez et al. proposed a very interesting hypothesis that the inhibition of proliferation by melatonin correlates with a decrease on intracellular ROS and increase of antioxidant defence systems, while induction of cell death correlates with an increase of intracellular ROS and decrease of antioxidant defences (45). In this context, melatonin should be considered as a redox modulator, not as a classical antioxidant.

Moreover, when referring to ROS-mediated anticancer effects, it is necessary to consider and specify the type of 
A

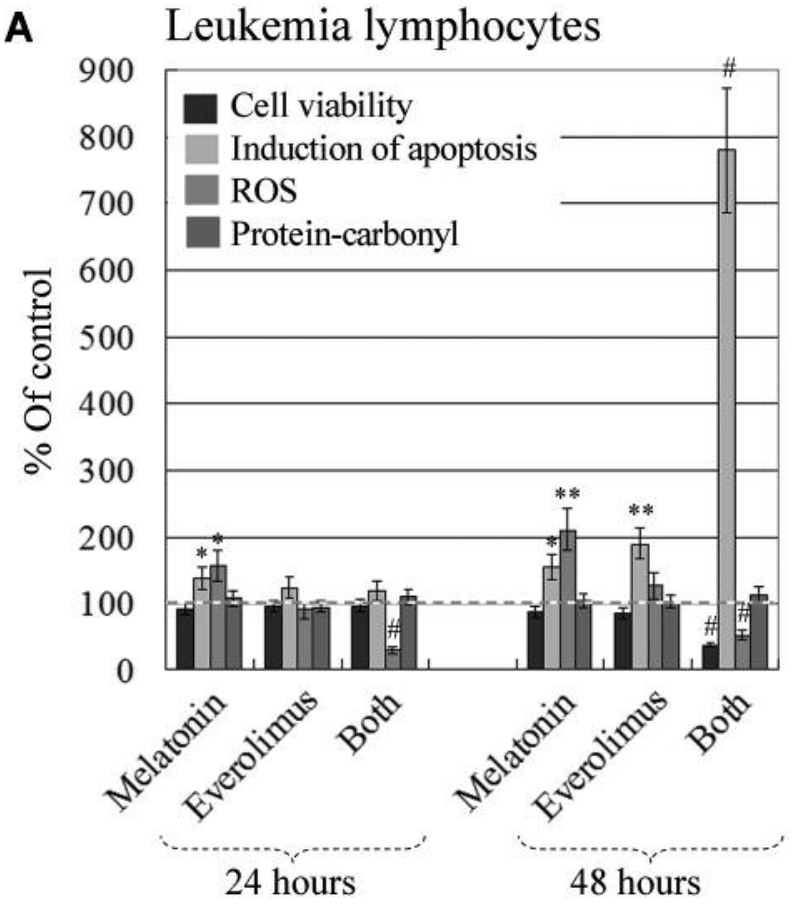

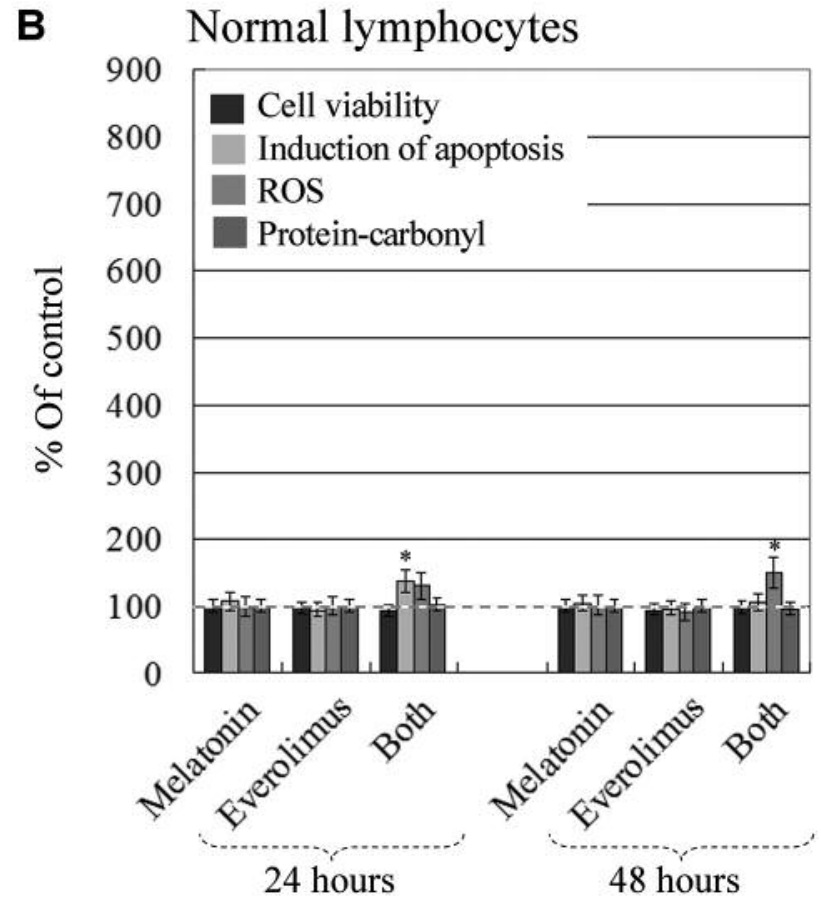

Figure 4. Effects of melatonin $(250 \mu \mathrm{M})$, everolimus $(5 \mu \mathrm{M})$ and their combination on cell viability, induction of apoptosis, level of reactive oxygen species $(R O S)$ and level of protein-carbonyl products in Jurkat leukemia cells $(A)$ and normal lymphocytes $(B)$, after 24-and 48 -h incubation at $37^{\circ} \mathrm{C}$ in humidified atmosphere. The data are the mean $\pm S D$ from three independent experiments. ${ }^{*} p<0.05,{ }^{*} p<0.01,{ }^{\#} p<0.001$ versus corresponding control.

A

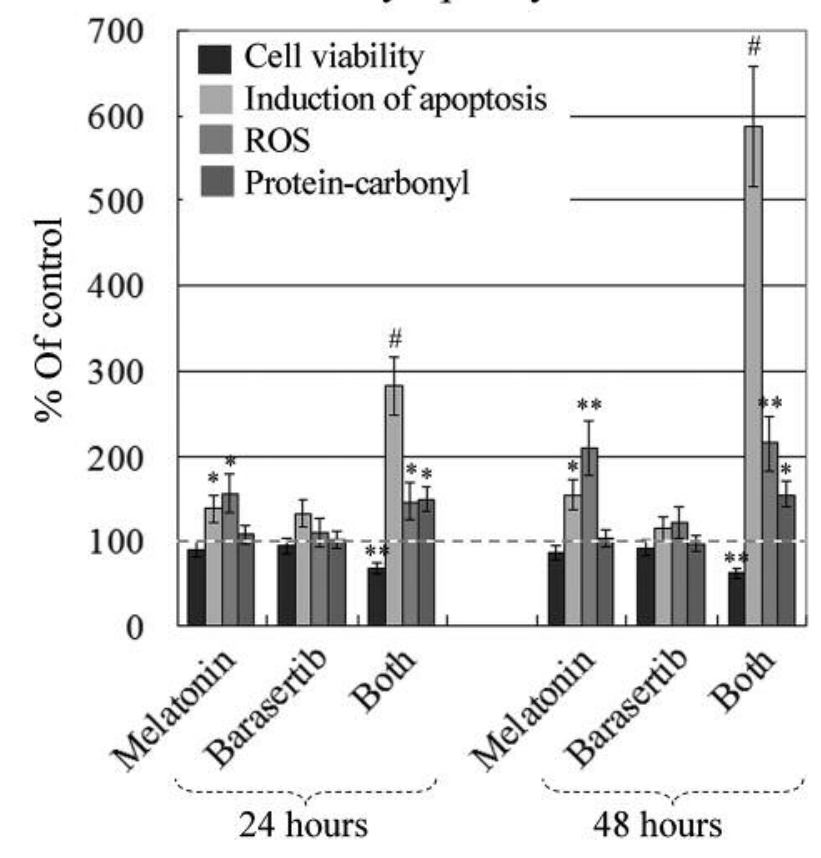

B

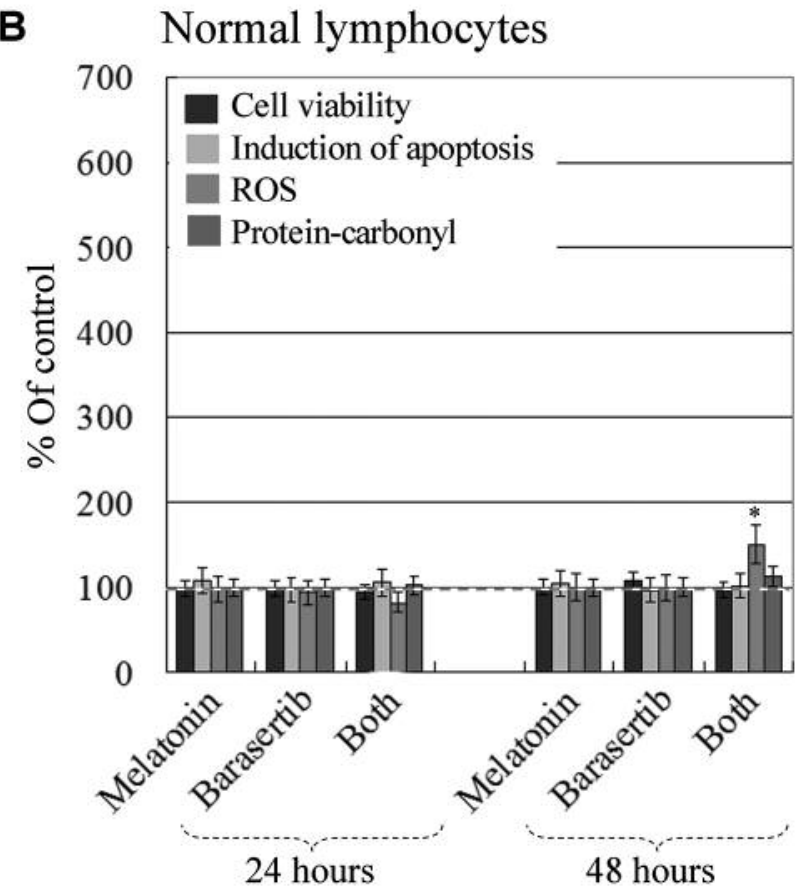

Figure 5. Effects of melatonin $(250 \mu \mathrm{M})$, barasertib $(0.01 \mu \mathrm{M})$ and their combination on cell viability, induction of apoptosis, level of reactive oxygen species (ROS) and level of protein-carbonyl products in Jurkat leukemia cells (A) and normal lymphocytes (B), after 24- and 48-h incubation at $37^{\circ} \mathrm{C}$ in humidified atmosphere. The data are the mean $\pm S D$ from three independent experiments. ${ }^{*} p<0.05, * * p<0.01,{ }^{*} p<0.001$ versus corresponding control. 
ROS. The ratio between main intracellular ROS (e.g superoxide and $\mathrm{H}_{2} \mathrm{O}_{2}$ ) might be crucial for the choice at cell signaling, proliferation or apoptosis, as well as for the metastatic potential of cancer cells. Dual effects of superoxide and $\mathrm{H}_{2} \mathrm{O}_{2}$ on cell-signaling regulation have been established and discussed in the literature. An interesting hypothesis has described by Pervaiz and Clement (48). The authors consider superoxide as 'oncogenic' ROS and $\mathrm{H}_{2} \mathrm{O}_{2}$ as 'oncosuppressive' ROS. They suggested that when the ratio is predominantly in favor of superoxide the cellular state inhibits apoptosis and promotes cell survival. If the ratio changes in favor of $\mathrm{H}_{2} \mathrm{O}_{2}$, this creates an intracellular environment suitable for induction of apoptosis and cell death. This hypothesis is well-grounded by numerous experimental and empirical observations on cells, animals and human, which indicate that: (i) almost all types of cancer cells are characterized by overproduction of superoxide and permanent oxidative stress due to their mitochondrial dysfunction and up-regulation of NADPH-dependent oxidase complex (NOX); (ii) $\mathrm{H}_{2} \mathrm{O}_{2}$ induces apoptosis in abnormal concentrations; and (iii) the overexpression of superoxide dismutase (SOD) and SOD mimetics abrogate the growth and proliferation of cancer cells in vitro and in vivo, which is indirect evidence for the oncosuppressive role of $\mathrm{H}_{2} \mathrm{O}_{2}(2$, 48-51). It seems that superoxide and $\mathrm{H}_{2} \mathrm{O}_{2}$ activate different signaling pathways with opposite consequences for cells survival or apoptosis.

The data in Figure 3 demonstrate that the combination of doxorubicin plus melatonin exhibited additive cytotoxic effect on both cell types - leukemia and normal. In Jurkat cells, the cytotoxicity was accompanied by low (control) levels of ROS and protein-carbonyl products, as well as by decreased expression of PSer on the cell surface, which indicates a suppression of apoptosis (Figure 3A). In normal lymphocytes, none of the parameters changed significantly compared to cells treated with doxorubicin only (Figure 3B).

Song et al. also reported that the increase in intracellular level of ROS in A549 lung cancer cells, which is necessary for the cytotoxicity of doxorubicin, was completely abolished upon melatonin co-treatment $(46,47)$. Granzotto et al. investigated the effect of melatonin on doxorubicininduced cytotoxicity towards human normal mammary epithelium HBL-100, mammary adenocarcinoma MCF-7, colon carcinoma LoVo, and mouse P388 leukemia cell lines, as well as on cancer cell sub-lines which are resistant to anthracyclines (53). Their data demonstrate that melatonin had minor effects on doxorubicin-induced cytotoxicity in parental human cell lines and their resistant sub-lines. In contrast, melatonin led to significant and dose-dependent sensitization to doxorubicin of resistant P388 leukemia cells (P388/ADR), which also occurs in vivo, as indicated by a significant increase in survival time of the hosts. These effects were accompanied by inhibition of P-glycoprotein- mediated doxorubicin efflux from cells co-treated with melatonin. In addition, melatonin abolished the disturbance of mitochondrial potential that occurs in doxorubicin-treated cells $(34,54)$.

At the same time, there is evidence which has shown that melatonin can be concomitantly administered with drugs to improve the therapeutic effect or to reduce adverse sideeffects (54-56). For example, Fic et al. reported that melatonin increased the cytotoxicity of doxorubicin towards human keratinocytes (primary culture), A569 non-small cell lung cancer, and HEp2 laryngeal cancer cell lines, significantly reducing cell numbers and inducing apoptosis in concentration-dependent manner (56). Plaimee et al. also showed that melatonin significantly augmented the cytotoxicity of cisplatin towards SK-LU-1 human lung adenocarcinoma cell line and increased the population of apoptotic cells by increasing mitochondrial membrane depolarization, activating the caspases cascade and inducing cell-cycle arrest in the S-phase, compared to cells treated with cisplatin alone (57).

Effect of melatonin on everolimus-induced cytotoxicity, apoptosis, production of ROS and protein-carbonyl products in leukemia and normal lymphocytes. We obtained more impressive data after combining melatonin with newgeneration chemotherapeutics, such as everolimus and barasertib. Everolimus is an inhibitor of the mammalian target of rapamycin (mTOR) pathway which plays a fundamental role in the regulation of cell viability, translational initiation, and cell-cycle progression. This drug is usually used in the clinic as an immunosuppressant to prevent rejection of organ transplants. In the past 10 years, it was found that everolimus also possesses anticancer activity (58-64). It sensitizes cancer cells to other anticancer drugs, as well as preventing the development of multidrug resistance through altering the balance between pro-apoptotic and anti-apoptotic factors $(61,64)$. Certain researchers have shown that the anticancer effect of everolimus was not mediated by increasing production of ROS (65), but others suggest the involvement of ROS in this process (66).

Our study shows that everolimus, at $5 \mu \mathrm{M}$, exhibited a slight cytotoxic effect ( $\sim 10-15 \%$ after 48 -hour incubation) towards leukemia lymphocytes but not towards normal lymphocytes (Figure 4). In Jurkat cells, the cytotoxicity of everolimus applied alone was accompanied by strong induction of apoptosis, but relatively slight (insignificant) increase of the level of ROS, and without change in the level of protein-carbonyl products. Melatonin increased the cytotoxicity of everolimus by up to $\sim 60-70 \%$ after 48 -h incubation with leukemia lymphocytes but the combination did not affect the viability of normal lymphocytes. In Jurkat cells, the combination exhibited a very strong induction of apoptosis ( $~ 8$-fold that of the control) but this effect was 
accompanied by a reduction of ROS even below that of the control (Figure 4A). In normal lymphocytes, the combination of everolimus plus melatonin did not affect the level of ROS nor the level of protein-carbonyl products, and did not induce apoptosis (Figure 4B).

Our data indicate that the high levels of ROS are not obligatory for induction of apoptosis in cancer cells, and particularly in leukemia lymphocytes. Obviously, the impressive induction of apoptosis and synergistic cytotoxicity of the combination of everolimus plus melatonin towards Jurkat cells is a result of ROS-independent mechanism(s).

Recently it was reported that melatonin down-regulates expression of $m T O R$, as well as other oncogenes [e.g. epidermal growth factor receptor 2 (HER2), p38 mitogenactivated protein kinase (MAPK), protein kinase B (p-AKT) and early growth response protein 3 (EGR3)], and upregulates tumour-suppressor genes [e.g. glypican 3 (GPC3)] $(67,68)$. This could explain the synergistic cytotoxicity of the combination of everolimus plus melatonin towards leukemia lymphocytes, as well as the differential effects on cell viability of leukemia and normal lymphocytes.

Effect of melatonin on barasertib-induced cytotoxicity, apoptosis, production of ROS and protein-carbonyl products in leukemia and normal lymphocytes. Barasertib belongs to a new class of pyrazoloquinazolines, selective inhibitors of aurora B kinase, discovered and described in 2007 (69). Currently, the aurora kinases are the subject of considerable interest as targets for the development of new anticancer agents. Little is known on the molecular mechanisms of action of barasertib, except that it inhibits aurora B kinase, provokes cell-cycle arrest and apoptosis, as well as enhancing the response to chemotherapy (70-72).

In our study, both cell types were treated with a very low concentration of barasertib $(10 \mathrm{nM})$. At this concentration, barasertib when applied alone did not affect the viability of either cell type (Figure 5). However, the combination of barasertib plus melatonin induced a strong cytotoxic effect on Jurkat cells ( $45-50 \%)$, which was accompanied by a strong induction of apoptosis (6-fold that of the control) and a relatively moderate enhancement of ROS and protein-carbonyl levels, as detected after 48-hour incubation (Figure 5A). In normal lymphocytes, the combination did not induce apoptosis and nor affected the level of protein-carbonyl products, but did induce a slight production of ROS (Figure 5B).

Clearly, the extremely strong induction of apoptosis and differential synergistic cytotoxicity of barasertib plus melatonin do not require production of ROS. Other mechanisms underlie these effects.

It has been demonstrated that aurora B kinase, which exists in a complex with survivin and mTOR, synergistically regulates survival and proliferation of leukemia and lymphoma cells via crass-talk with AKT, mTOR and
NOTCH signaling pathways $(73,74)$. Moreover, several studies have reported that aurora kinase inhibitors induce cell-cycle arrest and apoptosis of cancer cells through p38 MAPK and AKT/mTOR signaling $(75,76)$. Therefore, the synergistic cytotoxicity of the combination of barasertib plus melatonin towards leukemia lymphocytes could be explained by amplification of the effects of both substances on both molecular targets - aurora B kinase and mTOR.

In conclusion, there are many data regarding sensitization of cancer cells to conventional anticancer drugs (such as doxorubicin, bleomycin, cisplatin) by melatonin $(34,46,47$, 53-57), but only a limited number of studies have described the effect of melatonin on the cytotoxicity of new-generation anticancer drugs (recently approved for clinical use or still in clinical trials) (75-77). There are no data about the effect of melatonin on the efficiency of new-generation anticancer drugs described in the present study: AZD7762 (a selective inhibitor of checkpoint kinases), ABT-737 (a selective inhibitor of BCL2 proteins), barasertib (a selective inhibitor of aurora B kinase), everolimus (mTOR inhibitor), lonafarnib (a farnesyltrasferase inhibitor), MG132, MLN-2238 and bortezomib (proteasome inhibitors), and palbociclib (a selective inhibitor of cyclindependent kinases). To our knowledge, our study is the first to report synergistic cytotoxicity of melatonin in combination with everolimus or barasertib, which is specific for cancer cells and particularly for Jurkat acute lymphoblastic leukemia cells. Both combinations are harmless for normal lymphocytes. The data suggest that melatonin is a promising supplementary component for anticancer therapy, allowing reduction of the therapeutic doses of barasertib and everolimus, minimizing their side-effects. This statement can also be made for all investigated anticancer drugs whose cytotoxicity increased by combining them with melatonin.

\section{Acknowledgements}

The study was partially supported by the Center of Innovation Program from the Japan Science and Technology Agency and by the Diversity Grant, NIRS-Chiba University, Japan (granted to R.B.).

\section{References}

1 Ozben T: Oxidative stress and apoptosis: impact on cancer therapy. J Pharm Sci 96: 2181-2196, 2007.

2 Trachootham D, Alexandre J and Huang P: Targeting cancer cells by ROS-mediated mechanisms: a radical therapeutic approach? Nat Rev Drug Discov 8: 579-591, 2009.

3 Ivanova D, Bakalova R, Lazarova D, Gadjeva V and Zhelev Z: The impact of reactive oxygen species in anticancer therapeutic strategies. Adv Clin Exp Med 21: 899-908, 2013.

4 Sterba M, Popelova O, Vavrova A, Jirkovsky E, Kovarikova P, Gersl V and Simunek T: Oxidative stress, redox signaling, and metal chelation in anthracycline cardiotoxicity and pharmacological cardioprotection. Antioxid Redox Signal 18: 899-929, 2013. 
5 Hoye AT, Davoren JE, Wipf P, Fink MP and Kagan VE: Targeting mitochondria. Acc Chem Res 41: 87-97, 2008.

6 Wondrak GT: Redox-directed cancer therapeutics: molecular mechanisms and opportunities. Antioxid Redox Signal 11: 30133069, 2009.

7 Mohindra P, Sinha RN, Andrews RJ and Khuntia D: Noncytotoxic radiosensitizers in brain radiotherapy: journey till the first decade of this millennium. Curr Cancer Drug Targets 12: 260-278, 2012.

8 Oronsky B, Oronsky N, Scicinski J, Fanger G, Lybeck M and Reid T: Rewriting the epigenetic code for tumor resensitization: a review. Transl Oncol 24: 626-631, 2014.

9 Zhelev Z, Ivanova D, Aoki I, Saga T and Bakalova R: 2-Deoxy$\mathrm{D}$-glucose sensitizes cancer cells to barasertib and everolimus by ROS-independent mechanism(s). Anticancer Res 35: 66236632, 2015.

10 Zhelev Z, Ivanova D, Lazarova D, Aoki I, Bakalova R and Saga T: Docosahexaenoic acid sensitizes leukemia lymphocytes to barasertib and everolimus by ROS-dependent mechanism without affecting the level of ROS and viability of normal lymphocytes. Anticancer Res 36: 1673-1682, 2016.

11 León J, Castroviejo D, Escames G, Tan D-X and Reiter RJ: Melatonin mitigates mitochondrial malfunction. J Pineal Res 38: 1-9, 2005.

12 Emens JS and Burgess HJ: Effect of light and melatonin and other melatonin receptor agonists on human circadian physiology. Sleep Med Clin 10: 435-453, 2015.

13 Manchester LC, Coto-Montes A, Boga JA, Andersen LP, Zhou Z, Galano A, Vriend J, Tan DX and Reiter RJ: Melatonin: an ancient molecules that makes oxygen metabolically tolerable. J Pineal Res 59: 403-419, 2015.

14 Srinivasan V, Spence DW, Pandi-Perumal SR, Brown GM and Cardinali DP: Melatonin in mitochondrial dysfunction and related disorders. Int J Alzheimers Dis 2011: 326320, 2011.

15 Martin M, Macias M, Escames G, León J and Castroviejo D: Melatonin but not vitamins $\mathrm{C}$ and $\mathrm{E}$ maintain glutathione homeostasis in t-butyl hydroperoxide-induced mitochondrial oxidative stress. FASEB J 14: 1677-1679, 2000.

16 Okatani Y, Wakatsuki A, Reiter RJ and Miyahara Y: Acutely administered melatonin restores hepatic mitochondrial physiology in old mice. Int J Biochem Cell Biol 35: 367-375, 2003.

17 Rodriguez MI, Escames G, Lopez LC, Garcia JA, Ortiz F, Lopez A and Castroviejo D: Melatonin administration prevents cardiac and diaphragmatic mitochondrial oxidative damage in senescence-accelerated mice. J Endocrinol 194: 637-643, 2007.

18 Tapias V, Escames G, López LC, López A, Camacho E, Carrion MD, Entrena A, Gallo MA, Espinosa A and Castroviejo D: Melatonin and its brain metabolite $\mathrm{N}$-acetyl-5-methoxykynuramine prevent mitochondrial nitric oxide synthase induction in Parkinsonian mice. J Neurosci Res 87: 3002-3010, 2009.

19 Cardinali DP, Furio AM and Brusco LI: Clinical aspects of melatonin investigation in Alzheimer's disease progression. Curr Neuropharmacol 8: 218-227, 2010.

20 Olcese JM, Cao C, Mori T, Mamcarz MB, Maxwell A, Runfeldt MJ, Wang L, Zhang C, Lin X, Zhang G and Arendash GW: Protection against cognitive deficits and markers of neurodegeneration by long-term oral administration of melatonin in a transgenic model of Alzheimer's disease. J Pineal Res 47: 82-96, 2009.
21 Poeggeler B, Thuermann S, Dose A, Schoenke M, Burkhardt S and Hardeland R: Melatonin's unique radical scavenging properties roles of its functional substituents as revealed by a comparison with its structural analogs. J Pineal Res 33: 20-30, 2002.

22 Antolin I, Rodriguez C, Sainz RM, Mayo JC, Uria H, Kotler ML, Rodriguez-Colunga MJ, Tolivia D and Menéndez-Peláez A: Neurohormone melatonin prevents cell damage: effect on gene expression for antioxidant enzymes. FASEB J 10: 882-890, 1996.

23 Escames G, Leon J, Macias M, Khaldy H and Acuna-Castroviejo D: Melatonin counteracts lipopolysaccharide-induced expression and activity of mitochondrial nitric oxide synthase in rats. FASEB J 17: 932-934, 2003.

24 Rodriguez C, Mayo JC, Sainz RM, Antolin I, Herrera F, Martin $\mathrm{V}$ and Reiter RJ: Regulatiom of antioxidant enzymes: a significant role for melatonin. J Pineal Res 36: 1-9, 2004.

25 Blask DE, Dauchy RT and Sauer LA: Putting cancer to sleep at night: the neuroendocrine/circadian melatonin signal. Endocrine 27: 179-188, 2005.

26 Srinivasan V, Spence DW, Pandi-Perumal SR, Trakht I and Cardinali DP: Therapeutic actions of melatonin in cancer: possible mechanisms. Integrative Cancer Ther 7: 189-203, 2008.

27 Sainz RM, Mayo JC, Rodriguez C, Tan DX, Lopez-Burillo S and Reiter RJ: Melatonin and cell death: differential actions on apoptosis in normal and cancer cells. Cell Mol Life Sci 60: 1407-1426, 2003.

28 Scott AE, Cosma GN, Frank M, Wells RL and Gardner HS: Disruption of mitochondrial respiration by melatonin in MCF-7 cells. Toxicol Appl Pharmacol 171: 149-156, 2001.

29 Perdomo J, Cabrera J, Estevez F, Loro J, Reiter RJ and Quintana $\mathrm{J}$ : Melatonin induces apoptosis through a caspase-dependent but reactive oxygen species-independent mechanism in human leukemia Molt-3 cells. J Pineal Res 55: 195-206, 2013.

30 Rubio S, Estévez F, Cabrera J, Reiter RJ, Loro J and Quintana $\mathrm{J}$ : Inhibition of proliferation and induction of apoptosis by melatonin in human myeloid HL-60 cells. J Pineal Res 42: 131$138,2007$.

31 Leja-Szpak A, Jaworek J, Pierzchalski P and Reiter RJ: Melatonin induces pro-apoptotic signaling pathway in human pancreatic carcinoma cells (PANC-1). J Pineal Res 49: 248-255, 2010.

32 Martin-Renedo J, Mauriz JL, Jorquera F, Ruiz-Andrés O, González P and González-Gallego J: Melatonin induces cellcycle arrest and apoptosis in hepatocarcinoma HepG2 cell line. J Pineal Res 45: 532-540, 2008.

33 Garcia-Santos G, Martin V, Rodriguez-Blanco J, Herrera F, Casado-Zapico S, Sánchez- Sánchez AM, Antolin I and Rodriguez C: Fas/Fas ligand regulation mediates cell death in human Ewing's sarcoma cells treated with melatonin. Br J Cancer 106: 1288-1296, 2012.

34 Andrabi SA, Sayeed I, Siemen D, Wolf G and Horn TF: Direct inhibition of the mitochondrial permeability trasition pore: a possible mechanism responsible for anti-apoptotic effects of melatonin. FASEB J 18: 869-871, 2004.

35 Rao MV and Narechania MB: The genotoxic effects of anticancer drug gossypol on human lymphocytes and its mitigation by melatonin. Drug Chem Toxicol 39: 357-361, 2016.

36 Jang SS, Kim WD and Park MY: Melatonin exerts differential actions on X-ray radiation-induced apoptosis in normal mice splenocytes and Jurkat leukemia cells. J Pineal Res 47: 147-155, 2009. 
37 Lialiaris T, Lyratzopoulos E, Papachristou F, Simopoulou M, Mourelatos C and Nikolettos N: Supplementation of melatonin protects human lymphocytes in vitro from the genotoxic activity of melphalan. Mutagenesis 23: 347-354, 2008.

38 Miller SC, Pandi-Perumal SR, Esquifino AI, Cardinali DP and Maestroni GJ: The role of melatonin in immuno-enhancement: potential application in cancer. Int $\mathrm{J}$ Exp Pathol 87: 81-87, 2006.

39 Kuznetsov AV, Margreiter R, Amberger A, Saks V and Grimm M: Changes in mitochondrial redox state, membrane potential and calcium precede mitochondrial dysfunction in doxorubicininduced cell death. Biochim Biophys Acta 1813: 1144-1152, 2011.

40 Bejarano I, Espino J, Marchena AM, Barriga C, Paredes SD, Rodrigues $\mathrm{AB}$ and Pariente JA: Melatonin enhances hydrogen peroxide-induced apoptosis in human promyelocytic leukemia HL-60 cells. Mol Cell Biochem 353: 167-176, 2011.

41 Buyukavci M, Ozdemir O, Buck S, Stout M, Ravindranath Y and Savasan S: Melatonin cytotoxicity in human leukemia cells: relation with its pro-oxidant effect. Fundam Clin Pharmacol 20: 73-79, 2006.

42 Radogna F, Sestili P, Martinelli C, Paololli M, Paternoster L, Albertini MC, Accorci A, Gualandi $G$ and Ghibelli L: Lipoxygenase-mediated pro-radical effects of melatonin via stimulation of arachidonic acid metabolism. Toxicol Appl Pharmacol 238: 170-177, 2009.

43 Pariente R, Pariente JA, Rodrigues AB and Espino J: Melatonin sensitizes human cervical cancer HeLa cells to cisplatin-induced cytotoxicity and apoptosis: effects on oxidative stress and DNA fragmentation. J Pineal Res 60: 55-64, 2016.

44 Laothong U, Hiraku Y, Oikawa S, Intuyod K, Murata M and Pinlaor S: Melatonin induces apoptosis in cholangiocarcinoma cell lines by activating the reactive oxygen species-mediated mitochondrial pathway. Oncol Rep 33: 1443-1449, 2015.

45 Sanchez-Sanchez AM, Martin V, Garcia-Santos G, RodriguezBlanco J, Casado-Zapico S, Suarez-Garnacho S, Antolin I and Rodroguez C: Intracellular redox state as determinant for melatonin antiproliferative vs. cytotoxic effects in cancer cells Free Radic Res 45: 1333-1341, 2011.

46 Song N, Kim AJ, Kim HJ, Jee HJ, Kim M, Yoo YH and Yun J: Melatonin suppresses doxorubicin-induced premature senescence of A549 lung cancer cells by ameliorating mitochondrial dysfunction. J Pineal Res 53: 335-343, 2012.

47 Uguz AC, Cig B, Espino J, Bejarano I, Naziroglu M, Rodriguez $\mathrm{AB}$ and Pariente JA: Melatonin potentiates chemotherapyinduced cytotoxicity and apoptosis in rat pancreatic tumor cells. J Pineal Res 53: 91-98, 2012.

48 Pervaiz S and Clement M-V: Superoxide anion: Oncogenic reactive oxygen species? Int J Biochem Cell Biol 39: 1297-1304, 2007.

49 Fulda S, Galluzzi L and Kroemer G: Targeting mitochondria for cancer therapy. Nat Rev Drug Discov 9: 447-464, 2010.

50 Trachootham D, Lu W, Ogasawara MA, Velle NR and Huang P: Redox regulation of cell survival. Antioxid Redox Signal 10: 1343-1374, 2008.

51 Sabharwal SS and Schumacker PT: Mitochondrial ROS in cancer: initiators, amplifiers or an Achilles' heel? Nat Rev Cancer 14: 709-721, 2014.

52 Oberley LW: Anticancer therapy by overexpression of superoxide dismutase. Antioxid Redox Signal 3: 461-472, 2001.
53 Granzotto M., Rapozzi V, Decorti G and Giraldi T: Effect of melatonin on doxorubicin cytotoxicity in sensitive and pleiotropically resistant tumor cells. J Pineal Res 31: 206-213, 2001.

54 Reiter RJ, Tan DX, Sainz RM, Mayo JC and Lopez-Burillo S: Melatonin: reducing the toxicity and increasing the efficacy of drugs. J Pharm Pharmacol 54: 1299-1321, 2002.

55 Xin Zh, Jiang S, Jiang P, Yan X, Fan C, Di S, Wu G, Yang Y, Reiter RJ and Ji G: Melatonin as a treatment for gastrointestinal cancer: a review. J Pineal Res 58: 375-387, 2015.

56 Fic M, Podhorska-Okolow M, Dziegiel P, Gebarowska E, Wysocka T, Drag-Zalesinska $\mathrm{M}$ and Zabel M: Effect of melatonin on cytotoxicity of doxorubicin toward selected cell lines (human keratinocytes, lung cancer cell line A-549, laryngeal cancer cell line HEp-2). In Vivo 21: 513-518, 2007.

57 Plaimee P, Weerapreeyakul N, Barusrux S and Johns NP: Melatonin potentiates cisplatin-induced apoptosis and cell cycle arrest in human lung adenocarcinoma cells. Cell Prolif 48: 6777, 2015.

58 Witzig TE, Reeder C, Han JJ, LaPlant B, Stenson M, Tun HW, Macon W, Ansell SM, Habermann TM, Inwards DJ, Micallef IN, Johnston PB, Porrata LF, Colgan JP, Markovic S, Nowakowski GS and Gupta M: The mTORC1 inhibitor everolimus has antitumor activity in vitro and produces tumor responses in patients with relapsed T-cell lymphoma. Blood 126: 328-335, 2015.

59 Daver N, Boumber Y, Kantarjian H, Ravandi F, Cortes J, Rytting ME, Kawedia JD, Basnett J, Culotta KS, Zeng Z, Lu H, Richie MA, Garris R, Xiao L, Liu W, Baggerly KA, Jabbour E, O'Brien S, Burger J, Bendall LJ, Thomas D and Konopleva M: A Phase I/II study of the mTOR inhibitor everolimus in combination with hyperCVAD chemotherapy in patients with relapsed/refractory acute lymphoblastic leukemia. Clin Cancer Res 21: 2704-2714, 2015.

60 Baraz R, Cisterne A, Saunders PO, Hewson J, Thien M, Weiss J, Basnett J, Bradstock KF and Bendall LJ: mTOR inhibition by everolimus in childhood acute lymphoblastic leukemia induces caspase-independent cell death. PLoS One 9: e102494, 2014.

61 Dengler J, von Bubnoff N, Decker T, Peschel C and Duyster J: Combination of imatinib with rapamycin or RAD001 acts synergistically only in Bcr-Abl-positive cells with moderate resistance to imatinib. Leukemia 19: 1835-1838, 2015.

62 Mancini M, Corradi V, Petta S, Martinelli G, Barbieri E and Santucci MA: mTOR inhibitor RAD001 (Everolimus) enhances the effects of imatinib in chronic myeloid leukemia by raising the nuclear expression of c-ABL protein. Leuk Res 34: 641-648, 2010.

63 Calabro A, Tai J, Allen SL and Budman DR: In vitro synergism of m-TOR inhibitors, statins, and classical chemotherapy: potential implications in acute leukemia. Anticancer Drugs 19: 705-712, 2008

64 Harituninians T, Mori A, O'Kelly J, Luong QT, Giles FJ and Koeffler HP: Antiproliferative activity of RAD001 (everolimus) as a single agent and combined with other agents in mantle cell lymphoma. Leukemia 21: 333-339, 2007.

65 Schwarz JBK, Langwieser N, Langwieser NN, Bek MJ, Seidl S, Eckstein H-H., Lu B, Schomig A, Pavenstadt $\mathrm{H}$ and Zohlnhofer D: Novel role of the CXC chemokine receptor 3 in inflammatory response to arterial injury: involvement of mTORC1. Circ Res 104: 189-200, 2009. 
66 Pignochino Y, Dell'Aglio C, Basiricò M, Capozzi F, Soster M, Marchiò S, Bruno S, Gammaitoni L, Sangiolo D, Torchiaro E, D'Ambrosio L, Fagioli F, Ferrari S, Alberghini M, Picci P, Aglietta $\mathrm{M}$ and Grignani $\mathrm{G}$ : The combination of sorafenib and everolimus abrogates mTORC1 and mTORC2 up-regulation in osteosarcoma preclinical models. Clin Cancer Res 19: 21172131, 2013.

67 Grazielle MF, Marcelo M, Camargo ICC, Domeniconi RF, Martinez FE and Chuffa LGA: Melatonin attenuates Her-2, p38 MAPK, p-AKT, and mTOR levels in ovarian carcinoma of ethanol-preferring rats. J Cancer 5: 728-735, 2014.

68 Lee SE, Kim SJ, Yoon HJ, Yu SY, Yang H, Jeong SI, Hwang SY, Park CS and Park YS: Genome-wide profiling in melatoninexposed human breast cancer cell lines identifies differentially methylated genes involved in the anticancer effect of melatonin. J Pineal Res 54: 80-88, 2013.

69 Mortlock AA, Foote KM, Heron NM, Jung FH, Pasquet G, Lohmann JJ, Warin N, Renaud F, De Savi C, Roberts NJ, Johnson T, Dousson CB, Hill GB, Perkins D, Hatter G, Wilkinson RW, Wedge SR, Heaton SP, Odedra R, Keen NJ, Crafter C, Brown E, Thompson K, Brightwell S, Khatri L, Brady MC, Kearney S, McKillop D, Rhead S, Parry T and Green S: Discovery, synthesis, and in vivo activity of a new class of pyrazoloquinazolines as selective inhibitors of aurora B kinase. J Med Chem 50: 2213-2224, 2007.

70 Porcelli L, Guida G, Quatrale AE, Cocco T, Sidella L, Maida I, Iacobazzi RM, Ferretta A, Stolfa DA, Strippoli S, Guida S, Tommasi S, Guida M and Azzariti A: Aurora kinase B inhibition reduces the proliferation of metastatic melanoma cells and enhances the response to chemotherapy. J Transl Med 13: 26, 2015.

71 Boeckx C, Op de Beeck K, Wouters A, Deschoolmeester V, Limame R, Zwaenepoel K, Specenier P, Pauwels P, Vermorken JB, Peeters $M$, Van Camp G, Baay $M$ and Lardon F: Overcoming cetuximab resistance in HNSCC: the role of AURKB and DUSP proteins. Cancer Lett 354: 365-377, 2014.
72 Azzariti A, Bocci G, Porcelli L, Fioravanti A, Sini P, Simone GM, Quatrale AE, Chiarappa P, Mangia A, Sebastian S, Del Bufalo D, Del Tacca $M$ and Paradiso A: Aurora B kinase inhibitor AZD1152: determinants of action and ability to enhance chemotherapeutics effectiveness in pancreatic and colon cancer. Br J Cancer 104: 769-780, 2011.

73 Song J, Salek-Ardakani S and Croft M: The kinases aurora B and mTOR regulate the G1-S cell cycle progression of $\mathrm{T}$ lymphocytes. Nat Immunol 8: 64-73, 2007.

74 Wang C, Chen J, Cao W, Sun L, Sun H and Liu Y: Aurora-B and HDAC synergistically regulate survival and proliferation of lymphoma cell via AKT, mTOR and Notch pathways. Eur J Pharmacol 779: 1-7, 2016.

75 Fu Y, Zhang Y, Gao M, Quan L, Qui R and Liu J: Alisertib indices apoptosis and autophagy through targeting the AKT/mTOR/MAPK/p38 pathway in leukemic cells. Mol Med Rep 14: 394-398, 2016.

76 Li JP, Yang YX, Liu QL, Pan ST, He ZX, Zhang X, Yang T, Chen XW, Wang D, Qiu JX and Zhou SF: The investigation of aurora kinase A inhibitor alisertib (MLN8237) induces cell cycle G2/M arrest, apoptosis, and autophagy via p38 MAPK and AKT/mTOR signaling pathways in human breast cancer cells. Drug Des Dever Ther 9: 1627-1652, 2015.

77 Vriend J and Reiter RJ: Melatonin as a proteasome inhibitor. Is there any clinical evidence? Life Sci 115: 8-14, 2014.

Received November 1, 2016

Revised November 24, 2016

Accepted November 29, 2016 